\title{
Dance and School Age Children's Psycho-Motor Development: The Oseretzky-Guilmain Test
}

\author{
Palumbo Carmen*, Pallonetto Lucia*** and Ambretti Antinea** \\ Department of Human, Philosophical and Educational Sciences, University of Salerno, Fisciano Salerno 84084, Italy
}

\begin{abstract}
The importance of the relationship between the integration of sensory inputs and motor actions has given rise to large number of researches that have demonstrated how it is a necessary function not only for good academic performance but also for a proper development of the organizational thinking. The ability of sensory-motor integration is today recognized a central role in the integral formation of the subject (Viviani, Stucchi 1992). The Italian National Guidelines for the curriculum of primary school of 2012 require the achievement of motor skills related to balance and motor coordination as one of the goals for skill development at the end of primary school, measurable through a different use of evaluation tools. Among the several motor assessment tests recognised by the international scientific community, the Oseretzky-Guilmain test could be considered among evaluation tools for the possible detection of the psychomotor age, referring in detail to three categories such as: "balancing" on one leg; "staying" with your eyes closed on your toes and "jumping" on one leg. The Salerno research group conducted a field research involving a sample of 320 children, aged 6-8, whose only the half part practicing sport (dance), who were given Oseretzky-Guilmain tests represents a valid instruments of assessing the general coordination and balance and their constitutive elements. The aim of the research has highlighted the importance of an use of motor evaluation assessment in the primary school that is required to bring out potentialities and plurality of limits of each pupil, which are essential for effective customized teaching planning of educational act. It has been shown that children practicing sport-dance in our study case, pass the above tests easier than those ones not doing any physical exercises.
\end{abstract}

Key words: Educational dance, psyco-motor, Oseretzky-Guilmain test.

\section{Introduction}

The scientific approval of the role played by the moving corporeity in all school segments has called for a necessary review of the curricular activities primarily focused on the body-kinesthetic channel, contributing to the ministerial redefinition of curricular guidelines in Italy.

Corresponding authors: Palumbo Carmen*, Senior researcher of Methods and Didactics of Motor Activities (ssd M-EDF / 01), at the Department of Human Sciences, Philosophy and Education of the University of Salerno, research field: research plan, discussion and conclusion; Ambretti Antinea**, Phd in Methodology of Educational research and training research, Lecturer of the Teaching Methods Motor Activities Laboratory (ssd M-EDF / 01) at the Department of Human Sciences, Philosophy and Education of the University of Salerno, research fields: Introduction; Pallonetto Lucia***, Ph.D. Student in Didactic Corporealities, Technology and Inclusion, at the Department of Human Sciences, Philosophy and Education of the University of Salerno, research fields: methodology, objective, sample, instrument, emerged data and results.
The current ministerial guidelines of 2012 are soliciting primary school teachers to search for new possible planning and planning itineraries for activities related to the various disciplinary fields, already starting from primary school.

From the first schooling the evaluation of motor skills would require a high level of specificity of the procedures, choices, actions, objectives, contents and methods, calling into question qualities, properties and specific aspects very different from those that characterize the other disciplinary fields.

The model of motor assessment that can be proposed in the school environment could be $t$ integrated with use of motor assessment tests able to identify and eventually ascertain the existence of motor difficulties and the related triggering causes.

The possible integration of diversified shape of motor evaluation in the didactic field opens a window 
of reflexion to consider the insertion of procedures and motor assessment steps in the curriculum by introducing procedures consistent with the school-curricular organization.

The educational context requires methods and didactics capable to respond to the educational needs of the educational institution, very different from those used by the world of sport and of instruments and assessment methods consistent with the objectives and goals set by the National Guidelines of the Ministry of Public Education of 2012 [1].

The evaluation of recreational motor activities in the scholastic field cannot therefore ignore a deep knowledge of the relationship between body, movement, structures, functions and regulatory laws of growth, aiming at the awareness of the child dynamic functions and needs. The ministerial documents referring to the childhood segment highlights the need for an ad hoc start path able to facilitate the progressive construction of skills and motor skills that can be used at multiple levels.

Through a brief examination of different theoretical models, we tried not only to demonstrate the difficulty of indicating a univocal and exhaustive definition of motor coordination but also to analyze and verify the real possibility of applying descriptors and specific indicators on the didactic level and on the docimological one, in pre-primary and primary Italian schools. Evaluation, when scholastically referred to complex areas such as coordination, requires the preliminary study and identification of the actions to be evaluated that can be real indicators of coordination.

The possible analysis of the executive movements but above all of the characteristics not only anatomical-physiological distinctive of each type of combined movement aimed to achieve a goal is, in the educational field, one of the main educational problems directly related to the difficulty for the role of the teachers of the childhood and primary school to be able to evaluate all the constitutive aspects of motor coordination. Even today in the Italian school too often we continue to rigidly evaluate not the single constituent elements of a motor execution, even if apparently simple as to run, to launch, to direct and to manipulate, but the final product of the motor action schematizing the happened acquisition of a competence general movement in a single synthesis judgment to express what the student knows and how to do in a given scholastic phase without offering in this sense, possible to think of docimological reflection on what he could potentially learns to do with the necessary teaching devices.

In this perspective, the possible use of motor assessment test batteries in the school context, allows teachers to obtain basic information on the initial motor level of the students in order to "acquire objective data on circumstances relevant to the diagnosis of the performance" [2] of the students "through a standardized procedure for measuring and analyzing" [2] the levels of maturation achieved so as to be able after to program the teaching activities in a manner consistent with the starting levels.

The use of motor assessment tests in educational contexts includes the systematic collection and interpretation of data that leads as an integral part of the educational-educative process to the definition of a value judgment that aims at educational action. It is evident that the methods of observation and observation tests according to Meinel require that "the expert teacher or trainer" also used a series of these indirect methods to set and correct the movement [2] emphasizing the importance of choice of tools aimed at activating attention.

\section{Objective}

The aim of the research work was to evaluate, through the use of the Oseretzky-Guilmain test, the balance and dynamic general coordination in fourth and fifth grade children in order to assess whether the psychomotor age corresponds to the chronological age and to identify the corresponding limits and potential 
of each student [3].

\section{Methodology}

The present research is configured as a field study, of a qualitative and quantitative nature.

It was developed in three phases:

Phase I: go to the place, or to the schools, for the acquisitions on the school-age sample, explanation to parents and teachers on the work that will be done and compilation of the releases.

Test administration:

- to gather in small groups of 10 children to communicate the objectives of the activities;

- the language must be essential and accompany the explanations of the exercises with practical demonstrations. The tone in which one is addressing must be calm, optimistic and encouraging;

- give children time to develop strategies before the start of the tests to then encourage reflection on what happened;

- stand aside during the execution of the tests;

- carefully follow the execution of the same without giving suggestions;

- stimulate the active participation of each student to allow them to think, see, understand, choose;

- do not judge a mobility difficulty negatively, but encourage them to try again.

Phase II: Data collection for the acquisition of information useful for defining motor development. This phase involves the collection of data on a sample of 320 children aged between 6-8 years.

Phase III: Closure of the research. Processing and analysis of the data collected were conducted, with the aim of drawing useful conclusions for the research field.

\subsection{Sample}

The Salerno research group conducted field research involving a sample of 320 children between 6 and 8 years old, of whom 160 play sports (dance) and 160 do not practice sports, who were given the
Oseretzky-Guilmain test, of which the two most significant types of tests were mainly used, which are aimed at assessing the psychomotor age of children and therefore indicate, in the case of non-correspondence whether it is necessary to intervene to correct any delays or minor disturbances of various kinds [4].

\subsection{Instruments}

The two tests administered are:

(a) Balance test

(b) General dynamic coordination test

Both tests must be different depending on the age of the child, even if only for a year of difference, because physical abilities change rapidly during development.

(a) Two tests were included in the balance test.

In the first one, the children were asked to stay balanced on one leg, keeping the other flexed against the knee of the stretched one. The arms: one stretched along the side and the other with the hand resting on the bent knee. This test must be performed 3 times for at least 10 seconds, during which it is important to observe if and which errors the subject makes. Possible mistakes are: losing your balance, opening your arms, not being able to keep your foot on your knee for as long as required, changing the position of your leg. In the second test, the children must remain with their eyes closed, not bandaged, keeping their balance on their toes, with their arms at their sides and their feet together. Also this test must be performed 3 times for at least 10 seconds, during which it is important to observe if and which errors the subject makes. Possible errors are: spreading the arms, opening the eyes, swinging excessively, changing the weight of the body.

(b) In the general dynamic coordination test we asked to jump on one leg and hold the other flexed at right angles, arms at your sides, push with the foot on which you jump a matchbox inside a box at 5 meters away. Each child was tested 3 times. Possible errors: placing the flexed foot on the ground, spreading the 
arms, not being able to center the box with the matchbox. Or he was asked to take and chase him with a step, make a halt at the foot and then jump on a chair kept by the teacher without the child's touching it with his hands. Possible mistakes: losing balance on arrival, touching the chair with hands, not being able to jump.

\subsection{Research Plan}

The progenitor of the psychomotor assessment tools is certainly the battery of Oseretzky that he himself alone or with the contribution of other authors has administered on several occasions and also alongside other tests [5].

The data obtained with this test can give elements that can be used in different addresses:

- we can highlight a clumsiness (or lack of agility),

- a slowness of movements,

- the presence of synkinesis,

- a poorly manifest left-handedness, or the absence of side dominance, can be highlighted [6].

Thanks to the use of the Oseretzky-Guilmain test it is possible to demonstrate that children who constantly practice dance, but in general any other sport, develop greater motor skills than others. This may seem obvious, but above all it allows us to demonstrate that motor activity does not only determine physical / motor development, but also significantly favors psychic development [7] and that both processes can interact and create sometimes crucial mutual stimuli [8].

In detail, subjects who have carried out constant psychomotor activity [17], if not even professional or competitive, develop otherwise dormant abilities of:

- concentration

- memory

- organization of thought

- organization of the movement

- constancy in effort

- static and dynamic balance

- self control
- determination

All these skills must be considered and organized in a didactic manner following an appropriate didactic-therapeutic plan, particularly in clinical cases and, in any case, in all other cases. In this way and through the use of tests ${ }^{2}$ in the school or in any case the teacher can strongly contribute to psychophysical changes, sometimes slow, but absolutely decisive for the character, for the autonomy and for the relationship of communication with the other and with himself [9].

\subsection{Emerged Data}

According to Oseresky-Guillman the positive result is obtained only when 1 test out of 3 succeeds. Instead we have established that the positive result was obtained when 2 trials out of 3 were successful, because we had noticed that it was too easy a goal for the children who habitually practice dance. So the significant result is that children accustomed to movement-dance pass tests of balance and general dynamic coordination much more easily than others and therefore have a chronological age always corresponding to the psychomotor age [3].

This means that the practice of dance ensures in most cases an equal and adequate psychomotor development in children [10].

\section{Results}

The balance test examined has shown that children who practice dance have more easily overcome at least 2 out of 3 tests and that through the right training, children have a greater awareness of their body and are able to react correctly and immediately to what teacher asks them. This happens even after only one year of dance, as the little dancers can understand in a faster, almost instinctive way, what is the right position to maintain in order to obtain the right result [11].

\footnotetext{
2 A General Test of Motor Impairment for Children D. H. Stott First published: October 1966 https://doi.org/10.1111/j.1469-8749.1966.tb01798.x-.
} 


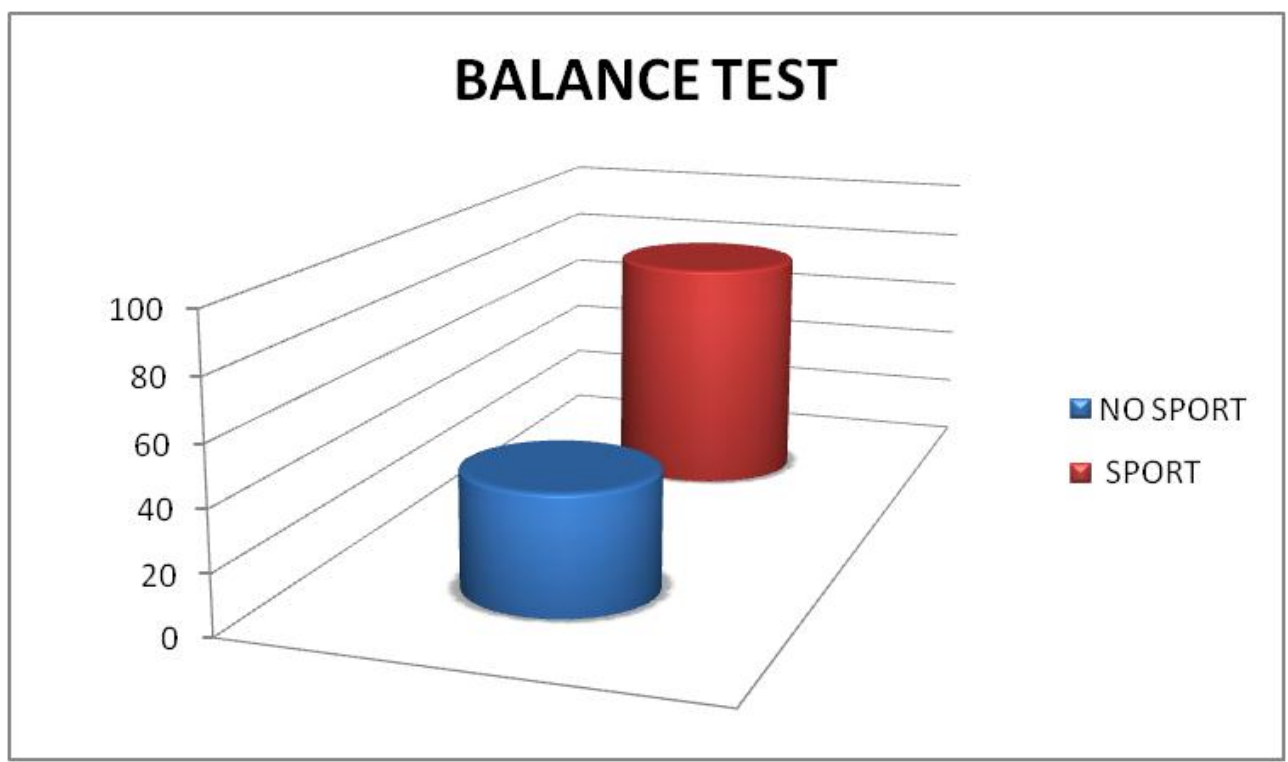

Fig. 1 Balance test in children who practice sports or not

In both groups of children, it was found to be more difficult to perform general dynamic coordination test.

It was observed that in the first group (dancers) the main difficulty was given by the type of exercise when it was oversized compared to their age and their experiences. In other words, not having yet studied all the positions and all the forms of balance and organization of space and body, organizing mentally and physically became an obstacle [12]. They even became a little embarrassed and often sorry that the exercise was not completed correctly. But this can be justified because children follow a study program based on age and therefore the growth is gradual.

In the second group we found instead a clear lower ability to concentrate and an unexpected inability to even understand which the right was and which the left was. 


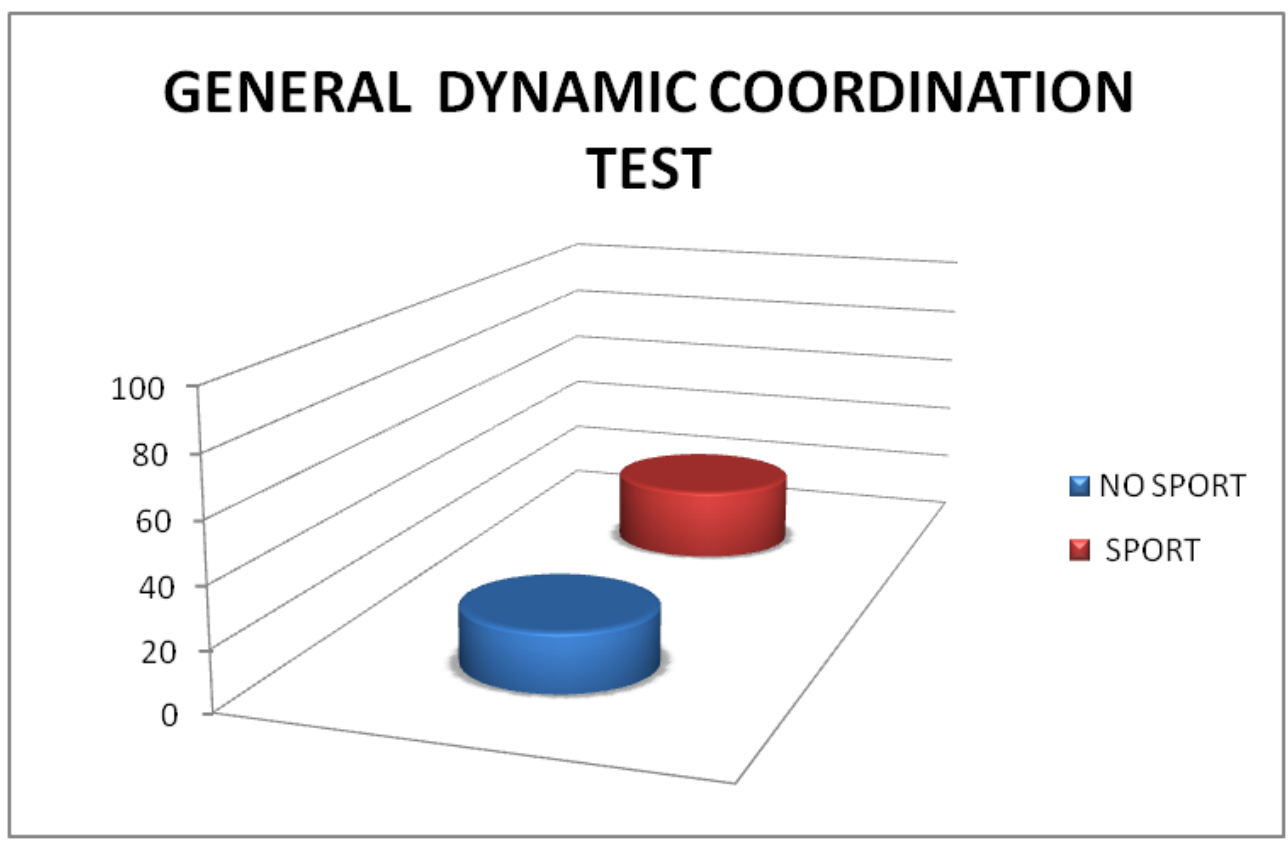

Fig. 2 General Dynamic Coordination test in children who practice sports or not

\section{Discussion and Conclusion}

Through its playful dimension, which however does not reduce its dignity and importance, which as we have seen is colossal, the educational dance can be an interesting attraction for the child and therefore more easily be used in the school as a didactic educational tool, because they are able to catch the attention.

It, through the music usage, work groups, the need for roles that fit together, is welcomed and favored by the youngest minds, always sensitive by nature to the playful aspect of any discipline [13].

The results of the research carried out, have shown that the educational dance, besides contributing to a better use and a possible improvement of the motor skills, helps the development of all the dimensions of the personality, favoring in an active and alternative way the learning processes and relationship skills [10].

All this brings down the old cornerstone that emphasized the mind-body dichotomy, demonstrating that the body is inclusive and above all, its correct stimulation through a meditated physical activity can favor the intertwined growth of the physical universe and the mental universe of a young person [14].

The educational dance is in itself integrative, not only when it is therapeutic, but every time it becomes an opportunity for recognition of one's identity and potential, thus generating the ability to give clear signals to the outside.

The youth, through dance-movement, is naturally induced to notice that a movement rather than another, a well-done step rather an un-studied step generate in himself and of those who are outside the emotions strictly connected to the surrounding space, to the music heard and at its rhythm and where they are present to the other subjects of the group [15].

The educational dance thus allows developing a movement in a creative form, giving the possibility to externalize the conscious expression of what is represented and animates in each one, awakening a multiplicity of new experiences, but at the same time leaving the freedom to express themselves and to communicate with the world surrounding the child [16].

Reading the most important acts on the subject of regulations concerning the use of dance as a didactic activity in primary school and kindergarten, we 
discover a new awareness of dance as an educational possibility and therefore a concrete predisposition to study the most profitable ways of inclusion of this discipline as a chance for the psychophysical growth of young people through school.

Through the elaboration of projects that confirm the didactic-movement-creativity link, it is possible to arrive at the definitive confirmation of the validity of an educational vision of corporeity as the main support for intellectual and creative development.

The international reading on the subject of motor evaluation in the infancy period suggests the need to pay attention both to the specificity of the motor assessment test and to the psychophysical characteristics of the reference target in the specific case of the students. The specificity of the contextual section to which the possible evaluation is addressed is no less important.

Primary school teachers entrust the essential part of the assessment to observation first, asking questions about the possible educational solutions to be undertaken to plan ad hoc activities. Of course the psychophysical specificity of each and every one would impose the need to go beyond the natural observation, even if fundamental, "alarm bell" and option for the choice of scientifically validated evaluation tools that respect both the didactic-organizational needs of the school and the specificity development of pupils. The choice of motor assessment tests becomes a necessary condition for a teaching team that chooses to investigate rigorously and to provide families with the small appropriate cognitive elements of each child that can be valid indicators for the deepening of the difficulties encountered by some children or simply for a cognitive enrichment of the specificities of each and every one.

The reference to motor evaluation tests seems to be a necessary condition for a cognitive investigation of the context section according to several points of view.

\section{References}

[1] Ministerial Guideline.D. M. 2012. "The New Indications for the Curriculum of the Nursery School and the First Cycle of Education.".

[2] Meinel, K. 1955. Theory of Movement: Sketch of a Theory of Sports Motility under the Pedagogical Aspect. Rome: Sport Press Society.

[3] Oseretzky, N. A. 1948. "A Scale for Studying the Capacity of Children." Journal of Clinical Psycology 12: 119-27.

[4] Lucangeli, D., Dupuis, M., Genovese, E., Rulli, G., eds. 2006. "Difficult Learning-Perception of Disorders and Difficulties at School." Quaderni of the National Center for Documentation and Analysis for Children and Adolescence, Florence, Istituto degli Innocenti. www.minori.it.

[5] Sloan, W. 1955. "The Lincoln-Oseretsky Motor Development Scale.” Genetic Psychology Monographs 51: 183-252.

[6] Massenz, M., and Simonetta, E. 2002. The Psychomotor Assessment. Franco Angeli, Milan.

[7] Berti E., Comunello F., Nicolodi G. (1988), The labyrinth and the traces. A therapy research child through non-verbal communication, Giuffré, Milan

[8] Cottini, L. 2003. Psychomotricity. Carocci Rome.

[9] Rink, J. E. 2002. Teaching Physical Education for Larning. New York, NY: McGraw-Hill.

[10] Schott-Billmann, F. 2011. "When the Dance Heals. Psychoanalytic and Anthropological Approach to the Therapeutic Function of Dance." FrancoAngeli Editore.

[11] Aucouturier, B., Darrault, I., and Empinet, J. L. 2009. "The Psychomotor Practice. Rehabilitation and Therapy." Armando Editore, Rome.

[12] Le Boulch, J. 2008. "Psychomotor Development from Birth to 6 Years." Armando Editore, Rome.

[13] Zagatti, F. 2009. The Educational Dance. Bologna: Mousikè-Educational Projects.

[14] Contini, M., Fabbri, M., and Manuzzi, P. 2006. "Not Just a Brain. Educate to Mind-Body-Meaning-Context Connections." Raffaello Cortina, Milan.

[15] Zagatti, F., in Laban, R. 2009. Modern Educational Dance. Macerata: Ephemeria Editrice.

[16] Le Boulch, J. 2005. "Psychomotor Development from Birth to Six Years." In The Body That Speaks. Communication and Expressiveness in Human Movement, edited by Casolo, F., and Melica, S. Milan: Life and Thought.

[17] Bertollo M., 2004."From skills to motor skills, In A. Carraro and M. Lanza, Teaching / Learning in physical education: problems and perspectives". Armando Editore. 